\title{
EXPOSIÇÃO OCUPACIONAL A COMPOSTOS ORGÂNICOS VOLÁTEIS NA INDÚSTRIA NAVAL
}

\author{
Maria de Fátima Barrozo da Costa* \\ Fundação Oswaldo Cruz, Centro de Estudos da Saúde do Trabalhador e Ecologia Humana / Escola Nacional Saúde Pública, Av. \\ Brasil, 4365, 21045-900 Rio de Janeiro - RJ \\ Marco Antonio Ferreira da Costa \\ Fundação Oswaldo Cruz, Escola Politécnica de Saúde Joaquim Venâncio, Av. Brasil, 4365, 21045-900 Rio de Janeiro - RJ
}

Recebido em 15/3/01; aceito em 14/9/01

\begin{abstract}
OCCUPATIONAL EXPOSURE TO VOLATILE ORGANIC COMPOUNDS IN THE NAVAL INDUSTRY. The scope of this study involved the evaluation of the concentration of some volatile organic compounds in the internal environmental air of a naval shipyard in the State of Rio de Janeiro, during painting activities in enclosed, semi-enclosed and open areas. Xylene was the volatile compound found in greatest abundance (25.20 to $191.66 \mathrm{ppm}$ ) in the locations researched. Benzene in the air, which is a carcinogenic substance, attained levels of $3.34 \mathrm{ppm}$ in semi-enclosed environments and the highest levels of toluene, xylene and n-butanol were found in the enclosed space of the ship. Results obtained highlight the need to establish air quality control programs in these internal areas, in order to safeguard the health of the workers.
\end{abstract}

Keywords: volatile organic compounds; occupational health; indoor air pollution.

\section{INTRODUÇÃO}

Os trabalhadores da indústria naval estão sujeitos a diferentes fatores de risco, como a exposição a compostos orgânicos voláteis, poeiras, fumos metálicos, ruídos e calor, principalmente, quando o trabalho ocorre em ambientes confinados. Estes espaços, inadequados, principalmente, devido à ausência de sistemas de ventilação e exaustão, são durante a reforma ou montagem do navio, o ambiente de trabalho, para diferentes atividades profissionais.

Compostos orgânicos voláteis, como o benzeno, tolueno, xilenos, n-butanol e metilisobutilcetona são comumente encontrados no ar durante o processo de pintura, provenientes da emissão de solventes orgânicos da tinta fresca ou utilizados para dissolver ou dispersar tintas, resinas e produtos de polimentos. Estas substâncias químicas atuam predominantemente sobre o sistema nervoso central como depressoras, que dependendo da concentração e do tempo de exposição, podem causar desde sonolência, tontura, fadiga até narcose e morte ${ }^{1}$.

$\mathrm{Na}$ indústria naval, a atividade de pintura, exige na maioria das vezes, um grande número de trabalhadores durante execução dos serviços, devido, não só ao tamanho das peças, como também, à necessidade de se finalizar a tarefa no menor tempo possível e durante a jornada diária de trabalho.

A má qualidade do ar interior desses locais, representa um risco à saúde humana, principalmente, se medidas de proteção individual e/ou coletiva não forem devidamente aplicadas de acordo com a necessidade imposta pelo serviço a ser executado.

Nesse contexto, o monitoramento ambiental, ferramenta importante, vem sendo introduzido de forma gradativa no país, para identificar e quantificar possíveis contaminantes presentes no ar ambiente, além de servir como instrumento de avaliação da eficiência dos procedimentos de controle de emissão instalados.

Assim, o objetivo deste estudo foi quantificar alguns poluentes no ar durante as atividades de pintura nos diferentes ambientes de um estaleiro de grande porte do Estado do Rio de Janeiro.

\section{MATERIAL E MÉTODO}

A avaliação ambiental ocorreu durante as atividades de pintura com pincel, rolo e pistola em três diferentes ambientes, perfazendo um total de 4 sítios de amostragens: ambiente confinado (\#1), situado no porão do navio e projetado com a finalidade de ser utilizado como frigorífico; ambiente semi-confinado (\#2 e \#3), cabines localizadas no pátio do estaleiro, próprias para receber peças ou blocos metálicos de grandes dimensões; e ambiente aberto (\#4), no convés do navio.

A concentração do benzeno, tolueno, xilenos, n-butanol e metilisobutilcetona no ar, foi avaliada, através da técnica de amostragem de área (Japan Association for Working Environment Measurement, 1991) ${ }^{2}$, utilizando-se tubo adsorvente de carvão ativado (SKC Inc., Valley View Road, USA), e bomba portátil, com fluxo contínuo de $0,2 \mathrm{~L}$ de ar por minuto, durante um período de 20 minutos, para cada ponto de coleta de ar. O número de pontos necessários ao estudo ${ }^{2}$, foi definido de acordo com o dimensionamento das áreas pesquisadas, em metros quadrados, eqüidistantes um dos outros pela mesma distância a partir de um ponto aleatório previamente selecionado.

A dessorção química dos compostos orgânicos voláteis, foi realizada com 2,0 mL de dissulfeto de carbono, seguida de agitação, repouso por 30 minutos e centrifugação. A fase orgânica, então separada, foi transferida para um frasco lacrado e analisada por cromatografia gasosa equipada com detector por ionização em chama (HP 5890 série II), de acordo com o método proposto por Rocha $(1997)^{3}$. As modificações realizadas foram: coluna capilar HP INOWAX (60 m x 0,25 mm D.I., 0,25 $\mathrm{mm}$ de espessura de filme); temperatura da coluna: $40{ }^{\circ} \mathrm{C}$ por $12 \mathrm{~min}$, de $40{ }^{\circ} \mathrm{C} \mathrm{a} 100{ }^{\circ} \mathrm{C}\left(5^{\circ} \mathrm{C} /\right.$ min) e de $100{ }^{\circ} \mathrm{C} \mathrm{a} 150{ }^{\circ} \mathrm{C}\left(10^{\circ} \mathrm{C} / \mathrm{min}\right)$; temperatura do detector e do vaporizador: $250{ }^{\circ} \mathrm{C}$ e $200{ }^{\circ} \mathrm{C}$, respectivamente. O modo de injeção foi com divisão de fluxo, taxa de divisão de 1:10. A quantificação foi realizada pelo método de padronização interna, utilizando-se tolueno deuterado, como padrão interno. O limite de detecção foi de $0,001 \mathrm{ppm}$, 0,020 ppm, 0,020 ppm, 0,010 ppm e 0,010 ppm para benzeno, tolueno, xileno, n-butanol e metilisobutilcetona, respectivamente. As

\footnotetext{
*e-mail: mafa@ensp.fiocruz.br
} 
taxas de recuperação média obtidas a partir do preparo de amostras com quantidades conhecidas de compostos orgânicos voláteis (benzeno, tolueno, xileno, n-butanol, metilisobutilcetona), foram superiores a 95\% e os coeficientes de variação, menores do que $17 \%$.

\section{RESULTADOS E DISCUSSÃO}

A caracterização dos ambientes estudados é apresentada na Tabela 1 e os resultados da avaliação ambiental mostrados na Tabela 2 .

A comparação das concentrações médias (média geométrica MG) dos compostos orgânico voláteis, entre os diferentes ambientes pesquisados, evidenciou níveis elevados das substâncias químicas, tolueno (32,99 ppm), xilenos (191,66 ppm) e n-butanol (10,15 ppm), no ar interior do ambiente confinado, enquanto os maiores valores, de benzeno (2,34 ppm e $0,85 \mathrm{ppm})$ e metilisobutilcetona (2,78 ppm) foram encontrados na avaliação do ar dos ambientes semi-confinados e do ar exterior no convés do navio, respectivamente.

O xileno, foi o composto orgânico volátil encontrado em maior abundância nos ambientes pesquisados, ultrapassando o Limite de Tolerância de 78 ppm, exigido pela Legislação Brasileira ${ }^{4}$. Nos ambientes semi-confinados a concentração máxima foi de $145 \mathrm{ppm}$ e no confinado, $320,2 \mathrm{ppm}$.

Tabela 1. Características dos locais selecionados, segundo o dimensionamento da área, temperatura do ar, umidade relativa do ar, pontos de coleta, trabalhadores envolvidos no processo de pintura e material utilizado na aplicação da tinta

\begin{tabular}{lcccc}
\hline & \multicolumn{4}{c}{ Locais } \\
& $\# 1$ & $\# 2$ & $\# 3$ & $\# 4$ \\
\hline Área $\left(\mathrm{m}^{2}\right)$ & 13 & 315 & 510 & 12 \\
Temperatura $(\underline{0} \mathrm{C})$ & 23 & 24 & 24 & 23 \\
Umidade relativa $(\%)$ & 84 & 81 & 85 & 83 \\
Pontos de coleta (n) & 6 & 14 & 17 & 7 \\
Trabalhadores (n) & 3 & 19 & 9 & 6 \\
Meio de aplicação & pincel/rolo & pistola & pistola & pistola \\
\hline
\end{tabular}

\#1: ambiente confinado; \#2, \#3: ambiente semi-confinado; \#4: ambiente aberto
Os níveis de benzeno no ar, substância carcinogênica ${ }^{5}$, no local \#2, e em alguns pontos de coleta do \#3, excederam o Valor de Referência Tecnológico (VRT) de 1 ppm, estabelecido pela Portaria № 14 da Secretaria de Segurança e Saúde no Trabalho - Ministério do Trabalho (SSST-MT) de dezembro de $1995^{4}$.

Os diferentes graus de confinamento dos ambientes pesquisados, a composição das tintas, o manuseio com diluentes orgânicos (solventes) e o meio de aplicação utilizado para aplicar a tinta (pincel, rolo, pistola), foram alguns dos fatores que influenciaram na emissão e dispersão dos vapores orgânicos por todo ambiente de trabalho, expondo os trabalhadores à diferentes concentrações durante as atividades de pintura.

Foi observado que as atividades de pintor e de auxiliar de pintura, eram exercidas, também, por funcionários com outras funções dentro da empresa, abrindo assim, o leque de expostos aos compostos orgânicos voláteis e solventes orgânicos.

O manuseio com as latas de tintas e diluição com solventes eram realizados sem equipamentos de proteção individual (EPI's). Apenas, alguns trabalhadores durante a aplicação da tinta com "spray", se equipavam com máscara de proteção para solvente ou sistema de ar mandado (máscara facial com linha de ar externo, via compressor), e a maioria, utilizava EPI's erroneamente (por exemplo, máscaras para poeira), ou simplesmente não usavam.

$\mathrm{Na}$ indústria naval, é visível a mudança do ambiente de trabalho à medida que a construção se concretiza e, especial atenção deve ser dada aos ambientes semi-confinados e confinados. Nos espaços semiconfinados, os sistemas de exaustão funcionaram em baixa potência durante as atividades de pintura, para evitar que a tinta secasse rapidamente, enquanto, nos confinados, nenhum sistema de ventilação forçada foi observado.

A formação de uma névoa durante o processo de pintura evidencia a importância do controle dos fatores de riscos à saúde associados à exposição aos compostos orgânicos voláteis, como o benzeno, É preciso ressaltar que ainda pouco se sabe sobre os possíveis efeitos à saúde devido a exposição à baixas concentrações ambientais e a longo prazo para as substâncias químicas que já têm os seus limites de tolerância estabelecidos pelos órgãos competentes ${ }^{6}$.

A probabilidade de se encontrar mais de uma substância química no ar, em ambientes ocupacionais, é muito grande e acontece com

Tabela 2. Concentração de compostos orgânicos voláteis no ar nos ambientes pesquisados (MG: média geométrica, DPG: desvio padrão geométrico; MIBC: metilisobutilcetona)

\begin{tabular}{|c|c|c|c|c|}
\hline & \multicolumn{4}{|c|}{ Locais } \\
\hline & $\# 1$ & \#2 & \#3 & \#4 \\
\hline \multicolumn{5}{|l|}{ Benzeno (ppm) } \\
\hline Faixa & $0,01-0,64$ & $1,51-3,34$ & $0,18-1,94$ & $0,30-0,40$ \\
\hline \multicolumn{5}{|l|}{ Tolueno (ppm) } \\
\hline $\mathrm{MG} \pm \mathrm{DPG}$ & $32,99 \pm 1,38$ & $5,18 \pm 1,78$ & $0,20 \pm 2,00$ & $6,34 \pm 1,68$ \\
\hline $\mathrm{MG} \pm \mathrm{DPG}$ & $191,66 \pm 1,37$ & $72,89 \pm 1,64$ & $57,63 \pm 1,65$ & $25,22 \pm 1,47$ \\
\hline Faixa & $137,4-320,2$ & $34,8-144,5$ & $24,4-145,9$ & $12,6-30,0$ \\
\hline \multicolumn{5}{|l|}{ n-Butanol (ppm) } \\
\hline $\mathrm{MG} \pm \mathrm{DPG}$ & $10,15 \pm 1,43$ & $0,29 \pm 3,33$ & $0,12 \pm 1,45$ & $1,42 \pm 2,39$ \\
\hline Faixa & $7,00-16,60$ & $0,10-0,74$ & $0,10-0,28$ & $0,30-2,10$ \\
\hline
\end{tabular}

\#1: ambiente confinado; \#2, \#3: ambiente semi-confinado; \#4: ambiente aberto 
bastante freqüência, possibilitando diferentes interações entre elas e conseqüentemente diferentes agravos ao organismo humano.

Vários estudos epidemiológicos ${ }^{7,8}$ registraram evidências de associação entre a profissão de pintor e incidência de leucemia, alertando para o fato de que o aparecimento dos primeiros sintomas e sinais pode ocorrer vários anos após terminada a exposição.

\section{CONSIDERAÇÕES FINAIS}

Diante da diversidade dos fatores de riscos presentes na indústria naval e por saber que a relação do homem com o meio ambiente que o cerca não é passiva, devido a sua capacidade de interagir com os fatores ambientais, torna-se necessário investir em medidas que possam melhorar a qualidade do ar interior, diminuindo, assim, a exposição ocupacional.

É preciso propor alternativas tecnológicas limpas, não poluidoras para o meio ambiente, rever os processos de trabalho; introduzir sistemas de exaustão e/ou ventilação eficientes que não prejudiquem a qualidade das peças recém pintadas; fazer uso de EPI's adequados para solventes orgânicos para todos os funcionários que se encontram na área durante o processo de trabalho.

Como instrumentos indispensáveis para avaliar os agravos à saúde e estabelecer estratégias de prevenção dos fatores de risco ocasionados pelo processo de trabalho, a avaliação ambiental, o monitoramento biológico e o exame médico dos funcionários devem se realizados periodicamente.

\section{AGRADECIMENTOS}

Os autores agradecem a colaboração dos consultores K. Mizunuma e T. Kawai, da Agência de Cooperação Internacional do Japão - JICA, pelo suporte técnico que proporcionou a realização deste trabalho.

\section{REFERÊNCIAS}

1. Phillips, M.; Gleeson, K.; Hughes, J.; Greenberg, J.; Cataneo, R.; Baker, L.; Mcvay, W.; Lancet 1999, 353, 1930.

2. Japan Association for Working Environment Measurement. Working Environment Measurement System in Japan. Japan: Ministry of Labour, 1991.

3. Rocha, L.S.; Tese de Doutorado, Universidade Federal do Rio de Janeiro, Brasil, 1997.

4. Segurança e Medicina do Trabalho, Manuais de Legislação, Editora Atlas: São Paulo, 1997.

5. World Health Organization, Occupational Health for all Biological Monitoring of Chemical Exposure in the Workplace, Geneva, v. 2, 1996.

6. Katsuyama, H.; Tsuchiya, G.; Saijoh, K.; Sumino, K.; J. Occup. Health 1998, 40, 186

7. Chen, R.; Seaton, A.; Cancer Detect. Prev. 1998, 22, 533.

8. Lundberg, I.; Milatou-Smith, R.; Scand. J. Environ. Health 1998, 24, 270. 